\title{
O FAZER RESISTÊNCIA NA LITERATURA: UM MOVER-SE DISSIDENTE POR "LAMPEJOS DE ESPERANÇA"
}

\section{MOUNTING RESISTANCE IN LITERATURE: A DISSIDENT MOVE BY "A GLIMMER OF HOPE"}

Fernanda Santos de Oliveira'

\begin{abstract}
RESUMO: Este estudo propóe uma discussăo a respeito das intersecçóes entre literatura e resistência a partir de narrativas poéticas que recriam os tempos de exceçâo marcados por memórias do medo e da dor e evidenciam a arte como um instrumento do resistir. Com o objetivo de explorar as imagens da resistência diante de contextos de exceçăo, empreendeu-se a análise de textos literários do período ditatorial brasileiro que compreendeu os anos de 1964 a 1985 e de suas reinvençôes na contemporaneidade. Como procedimento teórico-metodológico, realizou-se uma pesquisa bibliográfica que possibilitou, a partir da noçăo da sobrevivência dos vaga-lumes, de Didi-Huberman, das artes de fazer táticas e estratégias, de Certeau, da estética da emergência de Laddaga e das perspectivas de estado de exceçăo de Agamben, ampliar as rotas de leitura dos poemas Agora náo se fala mais, de Torquato Neto, Da resistência, de Lara de Lemos, as composiçóes Cálice, de Gilberto Gil e a versăo de Criolo. Conclui-se que, a partir da compreensăo da arte como subversâo criativa, entre as circularidades da estética e do político, é possível reconhecer contrapontos às versóes dos discursos oficiais que invisibilizam as vozes e os protagonismos de grupos dissidentes.
\end{abstract}

Palavras-chave: literatura; resistência; estado de exceçăo; política.

ABSTRACT: This study proposes a discussion about the intersections between literature and resistance from poetic narratives that recreate the exception times marked by memories of fear and pain and it evidences art as an instrument of resistance. With the objective of analyzing the images of the resistance to exception contexts from the analysis of literary texts of the Brazilian dictatorial period that comprised the years between 1964 and 1985 and its reinventions in contemporaneity, as a theoreticalmethodological procedure, a bibliographical investigation was carried out. It allowed the aesthetics from the notion of fireflies survival by Didi-Huberman, the arts to make tactics and strategies by Certeau, the emergence aesthetics by Laddaga and the perspectives of exception state by Agamben to broaden reading routes of the poems Agoara náo se fala mais, by Torquato Neto, Da resistência, by Lara de Lemos, the compositions Calice, by Gilberto Gil and the version of Criolo. We can conclude

1 Doutoranda em Literatura e Cultura pela Universidade Federal da Bahia - UFBA, Técnica em Assuntos Educacionais do Instituto Federal de Educaçâo, Ciência e Tecnologia Baiano - IFBaiano. E-mail: fer soliveira@hotmail.com 
that from the understanding of art as creative subversion, between the aesthetic and political circularities, it is possible to recognize counterpoints to the versions of the official discourses that conceal the voices and empowerment of dissident groups.

Keywords: literature; resistance; state of exception; politics.

\section{INTRODUÇÃO}

É que respirar gera movimento. Estar vivo impossibilita a fixidez. Regina Dalcastagnè

À sombra do golpe, mas traduzindo lampejos da resistência, a epígrafe acima de autoria de Regina Dalcastagnè, professora titular da Universidade de Brasília, foi mencionada em sua apresentaçăo intitulada Literatura e resistência no Brasil hoje, na mesa Artes e Revoluçăo, no XV Congresso Internacional da Associaçăo Brasileira de Literatura Comparada (ABRALIC), na Universidade do Estado do Rio de Janeiro (UERJ), em 9 de agosto de 2017. A vida pressupóe movimento e um deslocar-se constante. E, muitas vezes, as circunstâncias históricas impóem estratégias para conter o movimento.

Pensar nas imbricaçōes da literatura e da resistência implica reconhecer seus movimentos e deslocamentos como uma linguagem que reinventa e reinterpreta 0 real e que faz da representação um ato político. Nesse sentido, o objetivo deste artigo é analisar as imagens da resistência diante de contextos de golpe a partir do diálogo entre textos literários da contemporaneidade e do período ditatorial brasileiro que compreendeu os anos de 1964 a 1985. Tempos que reservaram memórias de medo e de dor e que fortaleceram a arte como um instrumento do resistir.

Literatura de resistência à opressâo da ditadura militar que movimenta deslocamentos de sentidos na representaçâo da alegoria política. A relaçâo dos oprimidos com o regime ditatorial năo é de submissăo exclusiva, mas de subversăo inventiva e criativa que tenta desestabilizar a ordem. Memórias dos sobreviventes de 1964-1985 que vêm à tona e que estabelecem um contraponto às versóes dos discursos oficiais que invisibilizam as vozes e os protagonismos de grupos dissidentes. Rumores do horror de 64 que ameaçam a paz e a democracia inscrevendo apariçóes fatídicas e tenebrosas.

Trata-se de uma contribuiçâo para pensar a respeito dos sujeitos que se movimentaram por meio da arte literária em contextos que impuseram a imobilizaçáo dos mesmos. Em um dos minicontos de 100 histórias colhidas na rua, de Fernando Bonassi, contista, romancista, dramaturgo, cineasta e roteirista, o escritor trata das possibilidades relacionais entre a fala, o movimento e o papel: $O$ que você fala pra mim, você pode falar pro papel. O que você fala de você, você pode falar pro papel. O que você fala pra você, você pode falar pro papel. O que você fala das coisas em movimento e do movimento das coisas, isso também você pode falar pro papel. (BONASSI, 1996, p. 59). A fala, o movimento e o papel săo retomados enquanto alegorias da expressăo e instrumentos da memória de tempos e espaços. 


\title{
IMAGENS DA RESISTÊNCIA: UMA SUBVERSÃO INVENTIVA
}

As obras literárias evocam memórias permitindo ao presente acessar fragmentos do passado e refletir sobre o futuro e suas incertezas. Por meio de inscriçōes de narrativas que extravasam a violência do período situam-se histórias de vida entrelaçadas com as marcas do social, do público e do furor do Estado. Tempos sombrios marcados por prisóes, torturas, assassinatos e exílios forçados daqueles que se opunham ao regime autoritário. É a instituiçăo do estado de exceçăo como paradigma de governo" que, conforme Agamben (2004, p.19), se constitui a partir da "aboliçáo provisória da distinçăo entre poder legislativo, executivo e judiciário". Em um contexto de censura e repressâo, manifestaçōes críticas e dissidentes resistiram aos ditames do sistema político. Segundo Bezerra (2014, p. 38),

Náo se pode esquecer que uma das justificativas para o golpe militar foi a necessidade de defender os valores familiares ante a ameaça comunista. De fato, um dos vetores que marcaram a orientaçăo ideológica do regime militar foi sua autocaracterizaçáo como uma instituiçâo guiada por princípios católicos e familiares. Quanto aos movimentos de resistência ao regime militar, no início a açâo ficou mais restrita às manifestaçóes públicas e ao setor da cultura, todavia, a partir de 1968, e mormente com a implementaçăo do AI-5, muitos desses jovens decidiram ingressar na luta armada.

Em tempos de desapariçóes forçadas, foram muitas as imagens construídas no campo literário para simbolizar a repressâo por meio de uma escrita a contrapelo que metaforiza os ocultamentos da palavra e a imobilizaçáo dos gestos. Torquato Neto, poeta, letrista e jornalista, viveu entre os anos de 1944 a 1972, destacando-se como um artista e militante da contracultura que contribuiu para o movimento tropicalista. $O$ artista também sofreu com a violência política do regime ditatorial sendo exilado em Londres e em Paris. Em seu poema Agora năo se fala mais evidencia a censura e a obsessâo estatal em conter o movimento:

\author{
Agora năo se fala mais \\ toda palavra guarda uma cilada \\ e qualquer gesto é o fim \\ do seu início: \\ Agora năo se fala nada \\ e tudo é transparente em cada forma \\ qualquer palavra é um gesto \\ e em sua orla \\ os pássaros de sempre cantam \\ nos hospícios.
}


Você náo tem que me dizer
o número de mundo deste mundo
náo tem que me mostrar
a outra face
face ao fim de tudo:
só tem que me dizer
o nome da república do fundo
o sim do fim
do fim de tudo
e o tem do tempo vindo:
náo tem que me mostrar
a outra mesma face ao outro mundo
(náo se fala. náo é permitido:
mudar de idéia. é proibido.)
náo se permite nunca mais olhares
tensôes de cismas crises e outros tempos.
está vetado qualquer movimento (TORQUATO NETO Apud PIRES, 2004, p. 168)

O poema já em seu primeiro verso alude ao presente como um tempo de proibiçōes: agora nâo se fala mais. O tempo da censura e da repressâo reconhece o poder simbólico da palavra de surpreender o inimigo como uma armadilha. Trata-se de um tempo da imobilizaçâo de gestos entendendo a palavra também como um gesto. 0 tempo do năo-movimento e do silêncio é instituído.

A poesia de Torquato Neto assemelha-se ao lampejo dos vaga-lumes remetendo-nos à seguinte reflexăo de Didi-Huberman: os tempos se tornam visíveis, assim como a própria história nos aparece em um relâmpago passageiro que convém chamar de 'imagem'? A intermitência da imagem (image-saccade) nos leva de volta aos vaga-lumes, certamente: luz pulsante, passageira, frágil. (DIDI-HUBERMAN, 2011, p. 46). Da mesma forma como o ano de 1975, é o momento, entăo, do desaparecimento das sobrevivências ou o desaparecimento das condiçôes antropológicas de resistência ao poder centralizado do neofascismo italiano", as palavras do poeta sugerem os tensionamentos de um tempo que aniquilou os movimentos.

Imagens que se assemelham à desesperança de Pasolini que "se desesperava de seu tempo", mas o que "desapareceu nele foi a capacidade de ver - tanto à noite quanto sob a luz feroz dos projetores - aquilo que năo havia desaparecido completamente". 
(DIDI-HUBERMAN, 2011, p. 64-5). Emergem-se gestos de tempos angustiantes que aterrorizavam os condenados à ditadura.

A escritora Lara de Lemos, uma das poetas engajadas politicamente, vivenciou a violência da ditadura brasileira, sendo aprisionada e torturada. Poeta, professora, jornalista e tradutora do Rio Grande do Sul, viveu entre os anos de 1923 e 2010. O poema Da resistência é parte do seu livro Inventário do Medo (1997). Sua escrita também é marcada pela memória da dor e da tortura que sofreu. Em seu poema expóe literariamente a forma como suas palavras duras e combatentes resistem:

Cantarei versos de pedras.

Năo quero palavras débeis para falar do combate.

Só peço palavras duras

uma linguagem que queime.

Pretendo a verdade pura:

a faca que dilacere,

o tiro que nos perfure,

o raio que nos arrase.

Prefiro o punhal ou foice

às palavras arredias.

Năo darei a outra face (LEMOS, 1997, p. 22).

Os versos de Lara de Lemos anunciam um enfrentamento por meio do canto de uma poesia sólida, dura e firme como uma pedra. O eu lírico recusa palavras frágeis e frouxas para a luta, pois para sua missâo apenas palavras abrasivas servem. A poeta solicita "palavras duras" ao tratar sobre o combate, fazendo alusâo a uma linguagem capaz de dilacerar, perfurar e arrasar. Rememorar a crueldade do regime nos faz pensar em como foi possível resistir em tempos tăo perversos. As palavras resistentes da poeta demonstram como as mulheres nâo foram receptoras passivas da opressâo mas, contrariamente ao que os silenciamentos tentam sugerir, foram aquelas que se destacaram nos processos de luta e contestaçâo.

Nessa perspectiva, "como os vaga-lumes desapareceram ou 'redesapareceram'? É somente aos nossos olhos que eles 'desaparecem pura e simplesmente'." (DIDIHUBERMAN, 2011, p. 47). Torquato Neto e Lara de Lemos sáo os sobreviventes da ditadura que reaparecem por meio da palavra eternizada na literatura. Palavras que oportunizam "conhecer os vaga-lumes, observando-os no presente de sua sobrevivência, reportando-se à acepçăo de Didi-Huberman (2011, p. 52).

Michel de Certeau (1998) analisa as práticas cotidianas enquanto práticas sociais que se traduzem como modos de agir a partir da reapropriaçấo e da experimentaçăo. 0 autor ressalta o quanto o individual está amalgamado com as fronteiras das vivências sociais. Nesse sentido, serăo lançados olhares sobre fragmentos da memória de um passado sob a ótica do presente a partir da análise da escrita literária de autores que expressaram a dor e angústia em tempos de repressăo política. Quais sâo as táticas e estratégias das práticas de resistência? Quais sâo as artes do resistir? 
Reinventar a partir de suas próprias regras. Como as estratégias săo impostas, os sujeitos forjam suas táticas de enfrentamento diante desse jogo de forças. Contexto em que $O$ Cálice se impóe e incomoda. Vive-se em estado de agonia no qual urge pelo afastamento do cale-se. A cançâo Cálice, proibida pela ditadura, foi composta em 1973 por Gilberto Gil e Chico Buarque. Com a morte do estudante Alexandre Vanucchi durante a repressâo ditatorial, o movimento estudantil organizou um show no qual a cançâo Cálice foi aclamada durante a apresentaçâo de Gil que recebeu a letra impressa numa folha de papel para que fosse possível atender ao pedido. E mais uma vez, o contexto político impóe a reaproximaçâo com o Cálice, imagem emblemática que simboliza a arte da dor e da resistência.

No dia 28 de julho de 2018, aconteceu no Rio de Janeiro o festival Lula Livre, um movimento histórico que defendeu a libertaçăo do ex-presidente Luiz Inácio Lula da Silva. A prisăo, em sua territorialidade enquanto instrumento de segregaçăo e opressâo, impossibilita a idiorritmia, termo cunhado por Barthes (2003) para se referir à possibilidade de conciliaçáo entre a vida coletiva e a individual. Nessa perspectiva, o estado de exceçấo também representou o cerceamento de processos idiorrítmicos ao impedir o equilíbrio entre o individual e o coletivo. Na oportunidade do festival, diversos artistas apoiaram o movimento e dentre eles Chico Buarque e Gilberto Gil retomaram a música Cálice, cançâo que tem se destacado no cenário político brasileiro por extravasar palavras-manifesto que expressam memórias sensíveis da dor, da repressáo e da tortura.

Lula escreveu um artigo, publicado na Folha de Sáo Paulo em julho de 2018, em resposta ao veto da Justiça que o proíbe de conceder entrevistas e gravar vídeos na prisāo, durante o período de campanha eleitoral para disputa presidencial. O texto recebeu o seguinte título: Afasta de mim esse cale-se. E, assim, mais uma vez a folha de papel (primeiro do movimento estudantil e agora de Lula) reaproxima Gilberto Gil do Cálice.

O trocadilho contemporâneo "Afaste de mim este cale-se", evocado intertextualmente no artigo de Lula, rememora a composiçâo Cálice de Gilberto Gil e Chico Buarque que faz uma súplica: "Pai, afasta de mim esse cálice". Cálice que transbordava sangue, amargura e dor. Se o poema de Lara Lemos clama pela verdade dura a composiçâo, que somente foi gravada em 1978 por Chico Buarque e Milton Nascimento, revela "tanta mentira, tanta força bruta" numa realidade desolada:

Como é difícil acordar calado

Se na calada da noite eu me dano

Quero lançar um grito desumano

Que é uma maneira de ser escutado

Esse silêncio todo me atordoa

Atordoado eu permaneço atento

Na arquibancada pra a qualquer momento

Ver emergir o monstro da lagoa (GIL; BUARQUE, 1973)

O calar-se que atormentava. A faca que já năo dilacera. E a "palavra presa na garganta" fazendo com o cálice uma alegoria de um passado frenético que impóe o silêncio como a ferramenta que assegura o apagamento das vozes dissidentes e que esconde perversidades e agruras. Conforme Laddaga (2012, p. 185), o período que compreendeu 
a segunda metade dos anos 1960 evidenciou um "momento de crise perceptível que movia os artistas à 'constataçăo estratégica de que, para 'fazer história', teria de haver uma reinvençâo expressiva capaz de, quer em uma 'anti', quer em uma 'hiperteatralidade' às vezes grotesca, paródica, expor a 'năo história' [...]".

Nesse sentido, quais săo os artifícios contemporâneos para se contrapor ao regresso de tempos temerosos? Desapareceram "os vaga-lumes? Desapareceram todos? Emitem ainda - mas de onde? - seus maravilhosos sinais intermitentes? Procuram-se ainda em algum lugar, falam-se, amam-se apesar de tudo, apesar do todo da máquina, apesar da escuridăo da noite, apesar dos projetores ferozes?" (DIDI-HUBERMAN, 2011, p. 45). Se a Música Popular Brasileira MPB protagonizou como uma das vias de resistência política nas vozes de Chico Buarque, Gilberto Gil, Caetano Veloso, Geraldo Vandré, dentre outras, hoje outras vozes ressoam: no rap, no funk, nos saraus, nos slams, na literatura de cordel, na cançấo popular, dentre outras. Sáo movimentos das periferias que expressam a resistência por outras vias - ao fazer poesia por meio da exploraçáo de temas e de uma linguagem que se aproxima do povo, por exemplo -, subvertendo a tradiçăo literária compreendendo esta conforme a acepçấo de Antonio Candido ao ressaltar que do "ponto de vista histórico, interessa averiguar como se manifestou uma literatura enquanto sistema orgânico, articulado, de escritores, obras e leitores ou auditores, reciprocamente atuantes, dando lugar ao fenômeno capital de formaçăo de uma tradiçăo literária". (CANDIDO, 2006, p. 99). O autor concebe a literatura como um sistema e, como tal, pressupóe uma rede de relaçóes entre autor, obra e leitor. Nessa perspectiva, é preciso compreender como se constituiu tal organicidade e articulaçăo do sistema literário.

A tradiçăo como uma invençâo é discutida por Pereira (2002) que destaca o seu processo de formaçăo a partir de um traçado linear e imaginário que numa perspectiva dialógica entre texto e contexto engendra maneiras de interpretaçăo. A questâo é que um único modo de interpretar torna-se o modelo. Portanto, para problematizar o processo de constituiçáo do sistema literário além de reconhecer a importância das múltiplas narrativas invisibilizadas historicamente é necessário estabelecer outras rotas de leitura para as obras já consagradas evidenciando as contradiçôes e ideologias imbuídas nos modelos canônicos de leitura. Maciel (1995, p. 22) enfatiza a reformulaçăo do conceito de tradiçăo a partir da concepçáo de Octavio Paz:

\footnotetext{
Um dos grandes méritos da literatura moderna, segundo Octavio Paz, foi reformular o conceito de tradiçáo a partir da perspectiva do novo. Se, no imaginário clássico, a reverência à tradiçăo se impunha como forma de se perpetuar o passado sem criticálo, os escritores modernos fundaram uma maneira criativa de com ela se relacionar: a via da negaçâo. Só que a negação, nesse caso, năo pode ser interpretada apenas como recusa ou destruiçáo, mas como crítica capaz de manter vivo o passado, de com ele dialogar de forma polêmica e usá-lo de um modo criador.
}

Assim, Octavio Paz promove deslocamentos da noçăo convencional de tradiçăo empreendendo movimentos que o associam ao novo e à negaçăo crítica. Numa movência incessante, é preciso questionar as limitaçōes que cercam os conceitos circunscritos a cada momento histórico e, portanto, situados em determinado contexto de modo a năo excluir obras e autores que desestabilizem a suposta continuidade e homogeneidade da tradiçăo. E uma das rotas possíveis é desestabilizá-la ao problematizar seus 
paradigmas, ampliar os conceitos limitados pelo "sistema articulado", possibilitar uma contra-leitura e reconhecer o potencial das narrativas que escapam aos ditames do discurso hegemônico.

O rapper Criolo, nome artístico de Kleber Cavalcante Gomes, em uma entrevista concedida à Revista Cult, fala de alguém que se permite viver, sofrer, enxergar o sofrimento do viver e a beleza que é respirar (CRIOLO, 2013, p. 8). Acrescenta que: "as cançóes e os poemas viram mero detalhe quando você vê o jovem indo para a rua. Ele é cançâo, a poesia, a força de um país. Entre continuidades e descontinuidades, Criolo (2007) também atualizou o Cálice, demarcando outros tempos e espaços em sua composição:

\author{
Como ir pro trabalho sem levar um tiro \\ Voltar pra casa sem levar um tiro \\ Se as três da matina tem alguém que frita \\ E é capaz de tudo pra manter sua brisa \\ Os saraus tiveram que invadir os botecos \\ Pois biblioteca năo era lugar de poesia \\ Biblioteca tinha que ter silêncio \\ E uma gente que se acha assim muito sabida \\ Há preconceito com o nordestino \\ Há preconceito com o homem negro \\ Há preconceito com o analfabeto \\ Mas năo há preconceito se um dos três for rico, pai \\ A ditadura segue meu amigo Milton \\ A repressăo segue meu amigo Chico \\ Me chamam Criolo e o meu berço é o rap \\ Mas náo existe fronteira pra minha poesia, pai
}

Nos versos de Criolo, evidencia-se a forma como a ditadura mantém seus laços de dominaçấo e opressâo. O preconceito social segrega e cala, seja por meio da violência das cidades, do elitismo ou através do silêncio das bibliotecas. No cálice de Criolo, ainda "escorre sangue, pai". A arma da palavra transpóe o silêncio e ecoa o grito da subversâo. Săo palavras-manifesto que aproximam o presente da sombra do passado. Segundo Agamben (2004, p. 57),

estar-fora e, ao mesmo tempo, pertencer: tal é a estrutura topológica do estado de exceçấ, e apenas porque o soberano que decide sobre a exceçăo e, na realidade, logicamente definido por ela em seu ser, e que ele pode também ser definido pelo oximoro êxtase-pertencimento.

E assim, o regime autoritário brasileiro é representado no Cálice, de Criolo, sob outras vestes e outros signos do terror. O espaço simbólico coincide com as ruas da 
periferia que se assemelham aos poróes da ditadura derramando sangue em suas calçadas. O mesmo espaço que promove deslocamentos nas configuraçóes dos processos de luta política. Sâo os saraus da periferia que evocam palavras que traduzem saberes ignorados pelo atroz sistema dominante, por meio de palavras subversivas e insubmissas.

Certeau (1998), ao analisar as práticas cotidianas como formas de atuaçăo do indivíduo nas relaçôes sociais, ressalta como o indivíduo reinventa a cultura para apreendê-la. O autor compreende a cultura popular como artes de fazer e observa a atuaçâo de uma lógica da instabilidade e a contrapelo. A arte do cotidiano é a arte do fazer diferente: "ali, sempre, os fortes ganham e as palavras enganam" (CERTEAU, 1998, p. 76). A alternativa é adotar uma linguagem e uma atitude próprias como linhas de fuga da opressăo. Qual é o instrumento de fuga em tempos de repressăo? Como se fazer ressoar a voz do oprimido perante o sistema que impera? Como inverter as relaçōes de força?

Na contemporaneidade, algumas linhas de fuga têm se sobressaído contra o autoritarismo e elitismo da tradiçăo literária. Contra o silêncio das bibliotecas, os slams enquanto concursos de poesia falada têm se destacado nas periferias como uma das formas de resistência que tem contribuído para o fazer literário a partir de outras perspectivas e apropriaçōes. Em 2016, aconteceu a primeira disputa internacional de slam da América Latina na Festa Literária das Periferias e já somam 80 slams em todo o Brasil.

Os saraus da periferia configuram-se como outra modalidade do resistir que clamam por leveza em tempos sombrios e caóticos. No lugar do silêncio, impera o contar de histórias e o recitar de poesias que săo compartilhadas. É a literatura sendo levada para lugares alternativos: galpóes, bares e botecos. Espaços onde a leitura em voz alta quebra o silêncio, năo permitindo calar-se de modo que, seja por meio de saraus ou através dos slams, muitos coletivos têm colaborado para o fortalecimento dos mecanismos de resistência da periferia.

Artistas que fazem da palavra um instrumento de luta pela democracia ocupando espaços alternativos e divulgando seus trabalhos por meio de redes sociais como Facebook, e por meio de editoras independentes. Săo caminhos traçados para subverter a ordem dominante. Conforme Certeau (1998, p. 79), existem diversas maneiras de jogar/desfazer o jogo do outro, ou seja, o espaço instituído por outros, caracterizam a atividade, sutil, tenaz, resistente, de grupos que, por năo terem um próprio, devem desembaraçar-se em uma rede de forças e de representaçōes estabelecidas. Tem que 'fazer com'. Nesses estratagemas de combatentes existe uma arte dos golpes, dos lances, um prazer em alterar as regras de espaço opressor."

Contrapondo-se à anulaçăo do protagonismo de diversos grupos sociais imposta pelos meios majoritários de produçâo discursiva, suas vozes evidenciam uma potencial capacidade de enfrentamento e de engendramentos de outras lógicas de sobrevivência. Contra-discursos sâo reelaborados com a finalidade de tensionar e perturbar a ordem do sistema ecoando ruídos da denúncia e da mobilizaçăo.

Em um dos seus minicontos, Fernando Bonassi trata da inércia e do ódio aos movimentos: Năo pode levantar. Simplesmente năo pode. Simplesmente năo sabe pra quê. Odeia fazer café. Odeia tirar os móveis do meio do caminho. Odeia escrever um recado. Odeia apanhar um dicionário pra decifrar as palavras que interrompem suas 
leituras [...] Odeia movimentos". (BONASSI, 1996, p. 203). Bonassi escreve literariamente sobre a inércia das pessoas que náo podem se levantar e năo sabem o pra quê, afinal os movimentos lembram o trabalho. Apesar dos estilhaços avassaladores que tentam imobilizar os dissidentes, eles se levantam e propagam lampejos de sobrevivência, subvertendo a inércia do cotidiano, descrita por Bonassi. Se nos discursos oficiais prepondera uma voz vigilante e autoritária que determina que nâo se pode levantar porque simplesmente năo pode, tal cerceamento năo é capaz de conter totalmente os grupos imbuídos do ideal da luta coletiva.

Conforme Didi-Huberman (2011, p. 58-9), Pasolini acreditava na desapariçấo dos vaga-lumes e esta teria sido a causa do luto do cineasta. Năo estava mais disposto ao movimento: "teriam as criaturas humanas de nossas sociedades contemporâneas, como os vaga-lumes, sido vencidas, aniquiladas, alfinetadas ou dessecadas sob a luz artificial dos projetores [...]?". Ainda acrescenta: 'náo existem mais seres humanos' aos olhos de Pasolini, nem comunidade viva. Há apenas signos a brandir. Nâo mais sinais a trocar. Năo há mais nada a desejar. Năo há entăo mais nada a ver nem a esperar. Os brilhos - como se diz, 'lampejos de esperança' - desapareceram com a inocência condenada à morte". O autor problematiza a desapariçấo dos vaga-lumes e o apagamento de sua própria luz enquanto escritor como também de sua esperança política.

\section{CONSIDERAÇÕES FINAIS}

Nesse sentido, espera-se que a literatura continue se destacando enquanto uma instituiçâo constituída por práticas sociais e sujeitos de uma mobilizaçâo transformadora de tal forma que o movimento das pessoas e seus gestos de resistência náo se resumam ao movimento dos pedintes na assustadora realidade das ruas, como bem descreve Bonassi:

UM PEDINTE BEM VESTIDO. No começo atribui seu estranhamento a essa incoerência; mas é quando o homem se aproxima um pouco mais pedinte e aleijado, montado nas muletas que ela nota o movimento do pedaço da perna. O movimento do coto, de um lado para outro com a sua assustadora realidade de membro. O músculo da coxa retorcendo-se para deslocar um joelho invisível. Nem a camisa de vincos impecáveis impede a bolha de ar que lhe sobe azeda. A parte morta da calça enrolada no passante do cinto. É mesmo assim, com essa espécie de nojo de Clarice, que ela espreme num instante o botăo do vidro elétrico, escondendo-se distraidamente por trás da transparência solar. (BONASSI, 1996, p. 149).

O pedinte com movimentos comprometidos, mas que ainda resistem pela sobrevivência simboliza o quanto o respirar pressupóe movimento. Numa sociedade que segue uma lógica perversa admitindo o transitar de alguns e impóe a fixidez de muitos, é urgente que o campo literário traduza as múltiplas perspectivas sociais. E, na luta pela sobrevivência, a literatura como uma arena em disputa apresenta linhas de fuga ao esquema determinista da opressấo. Segundo Certeau (1998, p. 86), năo se dá por acaso que toda a sua cultura se elabora nos termos de relaçôes conflituais ou competitivas entre mais fortes e mais fracos e, portanto, nâo existe neutralidade e nem submissâo completa. 
Entre os movimentos, o deslocar-se e o respirar, as imagens da resistência presentes na intervençâo de Dalcastagnè repetem-se na arte literária. Trata-se de combates ou de jogos entre o forte e o fraco, e das 'açóes' que o fraco pode empreender." (CERTEAU, 1998, p. 97). Nessa perspectiva, a análise das formas de resistência na literatura ao estado de exceçấo, pode contribuir para o fortalecimento da compreensăo da arte enquanto potência capaz de promover uma reflexăo sobre o presente a partir de fragmentos memorialísticos e de suas imbricaçôes com um passado nâo muito distante. Sáo as experiências do presente e do passado que possibilitam novos horizontes para as incertezas do futuro. E que a arte possa ser um dos pontos de equilíbrio idiorrítmico para a vida em sociedade.

\section{REFERÊNCIAS}

AGAMBEN, Giorgio. O Estado de Exceçâo. Săo Paulo: Boitempo, 2004.

BARTHES, Roland. Como viver junto: simulaçóes romanescas de alguns espaços cotidianos. Tradução Leyla Perrone-Moisés. Sáo Paulo: Martins Fontes, 2003.

BEZERRA, Kátia da Costa. Que bom te ver viva: vozes femininas reivindicando uma outra história. Estudos de literatura brasileira contemporânea, Brasília, n. 43, p. 35-48, jan./ jun. 2014. Disponível em:〈http://periodicos.unb.br/index.php/estudos/issue/view/927〉. Acesso em: 09 jul. 2018.

BONASSI, Fernando. 100 histórias colhidas na rua. Săo Paulo: Scritta, 1996.

BUARQUE, Chico; GIL, Gilberto. Cálice. 1973. Disponível em: <http://www.chicobuarque. com.br/construcao/mestre.asp?pg=calice_73.htm>. Acesso em: 09 jul. 2018.

CANDIDO, Antonio. Literatura e Sociedade. 9. ed. Rio de Janeiro: Ouro sobre Azul, 2006.

CERTEAU, Michel de. A invençāo do cotidiano: artes de fazer. 3. ed. Traduçăo Ephraim Ferreira Alves. Petrópolis: Vozes, 1998.

CRIOLO. Cálice. 2007. Disponível em: 〈https://www.letras.mus.br/criolo/1807067/>. Acesso em: 09 jul. 2018.

DIDI-HUBERMAN, Georges. A sobrevivência dos vaga-lumes. Traduçăo Vera Casa Nova e Márcia Arbex e revisăo de Consuelo Salomé. Belo Horizonte: Ed. UFMG, 2011.

LADDAGA, Reinaldo. Estética da emergência. Traduçăo Magda Lopes. Săo Paulo: Martins Fontes, 2012.

LEMOS, Lara de. Inventário do medo. Sâo Paulo: Massao Ohno Editor, 1997. 
MACIEL, Maria Esther. Os paradoxos do novo: sobre o conceito de tradiçăo na obra de Octavio Paz. Revista de Estudos de Literatura. Belo Horizonte, v. 3, p. 21-33, 1995.

PEREIRA, Márcio Roberto. A invençăo da tradiçăo. Terra roxa e outras terras - Revista de Estudos Literários. v. 1, p. 32-49, 2002.

PIRES, Paulo Roberto (Org.). Torquato Neto: Torquatália - do lado de dentro. Rio de Janeiro: Rocco, 2004. 